\title{
Centrifugação: Uma Alternativa Para Purificação de Biodiesel ${ }^{1}$
}

Janaína Fernandes Medeiros ${ }^{2}$, Thiago Luiz Belo Pasa ${ }^{3}$, Fernanda Naiara Campos de Almeida ${ }^{3}$, Maria Carolina Sérgi ${ }^{4}$, Nehemias Curvelo Pereira ${ }^{5}$, Oswaldo Curty da Motta Lima ${ }^{5}$

1 Aceito para publicação no $3^{\circ}$ Trimestre de 2014

2 Doutoranda em Engenharia Química na Universidade Estadual de Maringá- UEM, janainafmedeiros1@ hotmail.com

3 Mestrandos em Engenharia Química na Universidade Estadual de Maringá- UEM, thiagopasa@hotmail.com; fnc.almeida@gmail.com

${ }^{4}$ Professora na Tecnologia em Processos Químicos na Universidade Tecnológica Federal do Paraná- UTFPR, mcarolinagomes@yahoo.com.br

${ }^{5}$ Professores do Departamento de Engenharia Química na Universidade Estadual de MaringáUEM, nehemiascp@yahoo.com.br; oswaldo@deq.uem.br

\section{Resumo}

Há um grande crescimento da produção de biodiesel no Brasil, que pode ser explicado pelas vantagens que o mesmo oferece e, por isso, surge a necessidade de estudos para otimização do processo de produção. O objetivo deste trabalho é analisar a purificação do biodiesel por meio de centrifugação, sem a retirada prévia do etanol. Para isso, o biodiesel foi produzido por transesterificação etílica de óleo de canola utilizando hidróxido de sódio como catalisador e purificado por centrifugação sem a pré-retirada do etanol. Os resultados inicialmente obtidos mostraram que não houve separação das fases. Como alternativa, foram adicionadas ao biodiesel, diferentes concentrações de água (5 e $10 \%$ ). O melhor resultado de centrifugação foi obtido com a adição de $10 \%$ de água, para uma rotação de 2000 rpm e um tempo de 5 minutos, mostrando que a centrifugação é muito eficaz para a purificação do biodiesel.

\section{Palavras-chave}

biodiesel, purificação, centrifugação. 


\begin{abstract}
Biodiesel production in Brazil is increasing significantly, which can be explained by its advantages. So, studies to optimize the production process become very important. In this context, the objective of this study is to analyze biodiesel purification by centrifugation without the previous separation of ethanol. Biodiesel was produced by ethyl transesterification of canola oil using sodium hydroxide as catalyst and purified by centrifugation without ethanol pre-removal. The results showed that initially there was no phase separation. So, as an alternative, different concentrations of water (5 to $10 \%$ ) were added to biodiesel. The best result was obtained by centrifugation with addition of $10 \%$ water, rotation of $2000 \mathrm{rpm}$ and a time of 5 minutes, showing that centrifugation is very effective for biodiesel purification.
\end{abstract}

\title{
Keywords
}

Biodiesel, purification, centrifugation.

\section{Introdução}

A produção de biodiesel no Brasil está em grande crescimento e esse crescimento pode ser explicado pelas vantagens que o biodiesel oferece. Segundo a Agência Nacional do Petróleo, Gás natural e Biocombustíveis - ANP, os biocombustíveis poluem menos por emitirem menos compostos no processo de combustão dos motores, além da tendência do processo de produção ser mais limpo.

De acordo com Parente (2003), biodiesel é um combustível renovável, biodegradável e ambientalmente correto, sucedâneo do óleo diesel mineral. É constituído de uma mistura de ésteres metílicos ou etílicos de ácidos graxos, obtidos da reação de transesterificação de qualquer triglicerídeo com um álcool de cadeia curta, como o metanol ou etanol.

Ao final da transesterificação, é necessário que sejam feitos processos de purificação do biodiesel, que consistem na remoção dos excessos de glicerol, álcool e demais elementos (água, sedimentos e odores) e também na neutralização dos catalisadores utilizados (DIB, 2010).

Gomes et al. (2013), estudaram o uso de adição de água acidificada na purificação de biodiesel por microfiltração e seus resultados mostraram um grande efeito na remoção de 
glicerol da fase de biodiesel. Esta remoção ocorre porque a adição de água promove a formação de uma fase aquosa, incluindo glicerina, sabão e etanol, formando aglomerados com tamanho médio maior do que o diâmetro dos poros da membrana.

A adição de água pode melhorar a separação de fases biodiesel/glicerol, pois segundo Saleh et al. (2010), a adição de uma concentração mássica de água ao biodiesel maior do que 0,06\% proporciona um aumento considerável dos aglomerados de glicerol. Os resultados obtidos pelos autores demonstraram que o tamanho dos aglomerados aumentou de $0,25 \mu \mathrm{m}$ na concentração de $0,06 \%$ para 3,0 $\mu \mathrm{m}$ com a adição de $0,2 \%$ de água.

Steluti (2007) avaliou a separação das fases de uma "mistura sintética" constituída de biodiesel, glicerina e etanol, por meio do processo de centrifugação. Neste estudo, foram avaliadas amostras com diferentes concentrações de etanol e avaliado o tempo de decantação da fase glicerina de diferentes amostras e constatado que a presença do etanol, realmente, aumenta a solubilidade do biodiesel na glicerina e vice-versa, agindo como um cossolvente e, dessa forma, dificultando o processo de separação dessas substâncias por decantação. Nos ensaios de centrifugação, variou-se o tempo de residência (2, 3 e 4 minutos), velocidade de rotação $(1000,2000$ e $3000 \mathrm{rpm})$, temperatura $\left(25,30\right.$ e $\left.55^{\circ} \mathrm{C}\right)$ e quantidade de etanol $(3,6$ e 9 mols) presente no meio, chegando nas melhores condições de operação da centrífuga: 1000 rpm, tempo de residência de 4 minutos e $25^{\circ} \mathrm{C}$ ou $3000 \mathrm{rpm}$, tempo de residência de 2 minutos e $25^{\circ} \mathrm{C}$.

Segundo Steluti (2007), entre as principais vantagens do processo de separação por centrifugação se destacam a separação de componentes que possuem pequena diferença de densidade; curto tempo de residência, ocupando pequeno volume na planta industrial, com menor geração de resíduos. Entretanto, as centrífugas são equipamentos caros; com alto custo de operação e manutenção e não trabalham em muitos estágios.

Uma forma de se verificar a eficiência da purificação é pela análise do teor de glicerol contido no biodiesel purificado. A ANP define uma quantidade máxima de $0,02 \% \mathrm{em}$ massa de glicerol no biodiesel.

Deste modo, o objetivo deste trabalho é analisar a purificação do biodiesel por meio de centrifugação, mostrando a viabilidade deste processo com relação ao processo convencional de purificação de biodiesel, que consiste em lavagens com água acidificada aquecida e posterior decantação.

\section{Materiais e métodos}


O óleo de canola bruto utilizado nos experimentos foi fornecido pela Cooperativa Agroindustrial Cocamar (Maringá, Paraná). O etanol anidro foi fornecido pela Usina Santa Terezinha (Tapejara, Paraná). O catalisador utilizado foi hidróxido de sódio de grau analítico, na forma de micropérolas, adquirido da Biotec.

O biodiesel foi produzido pela reação de transesterificação, conduzida em balão de três bocas equipado com um agitador mecânico e um termômetro, imerso em um banho térmico. Foram utilizadas as condições do planejamento experimental de Gomes et al. (2012) com os dados de razão molar, temperatura, tempo de agitação e rotação que proporcionaram os maiores rendimentos em ésteres etílicos. Para cada reação, foram colocadas $1000 \mathrm{~g}$ de óleo no balão, que permaneceu sob agitação até que se atingisse a temperatura desejada de $30^{\circ} \mathrm{C}$. Foram previamente misturados $10 \mathrm{~g}$ de hidróxido de sódio e $390 \mathrm{~g}$ do etanol até completa dissolução do catalisador e adicionados ao balão, onde a mistura permaneceu sob agitação em torno de $350 \mathrm{rpm}$, por uma hora.

Para a centrifugação utilizou-se um planejamento DCCR (Delineamento Composto Central Rotacional) com 2 variáveis (tempo e rotação) e 4 repetições no ponto central. A rotação variou de 1000 a 7000 rpm e o tempo de 1 a 30 minutos.

Buscando eliminar a etapa previa de retirada do etanol, o processo de purificação foi realizado por centrifugação, por meio das seguintes propostas:

1) Centrifugação do biodiesel sem a pré-retirada do etanol.

2) Centrifugação do biodiesel sem a pré-retirada do etanol com tratamento prévio: adição de água nas concentrações de 5 e $10 \%$.

A avaliação da eficiência da centrifugação na separação das fases (biodiesel e glicerol) foi feita por meio da análise do teor de glicerol livre, realizada pelo método titulométrico (metodologia modificada, baseada no método oficial da AOCS (Ca 14-56)).

\section{Resultados e discussão}

Na primeira etapa, o processo de centrifugação sem tratamento prévio não promoveu a separação das fases glicerol e biodiesel em nenhuma das condições operacionais estudadas (rotação e tempo). Isso pode ser explicado pelo fato do etanol ser um cossolvente (solubiliza produtos polares e apolares), fazendo com que o glicerol permaneça dissolvido no biodiesel. Steluti (2007) estudando a purificação de biodiesel por centrifugação de amostras "sintéticas" 
de uma mistura de biodiesel, glicerol e etanol, obteve uma separação de fases completa. Como no presente trabalho foi estudada a separação de uma amostra "real" resultante da produção de biodiesel e não uma amostra sintética, a não separação de fases pode ser explicada devido à presença de outros componentes nesta amostra "real".

Nas próximas etapas, foram adicionadas às misturas resultantes da reação, diferentes proporções de água. A Figura 1 apresenta os resultados do teor de glicerol contido no biodiesel após as centrifugações com adição de 5 e 10 \% de água ao biodiesel.

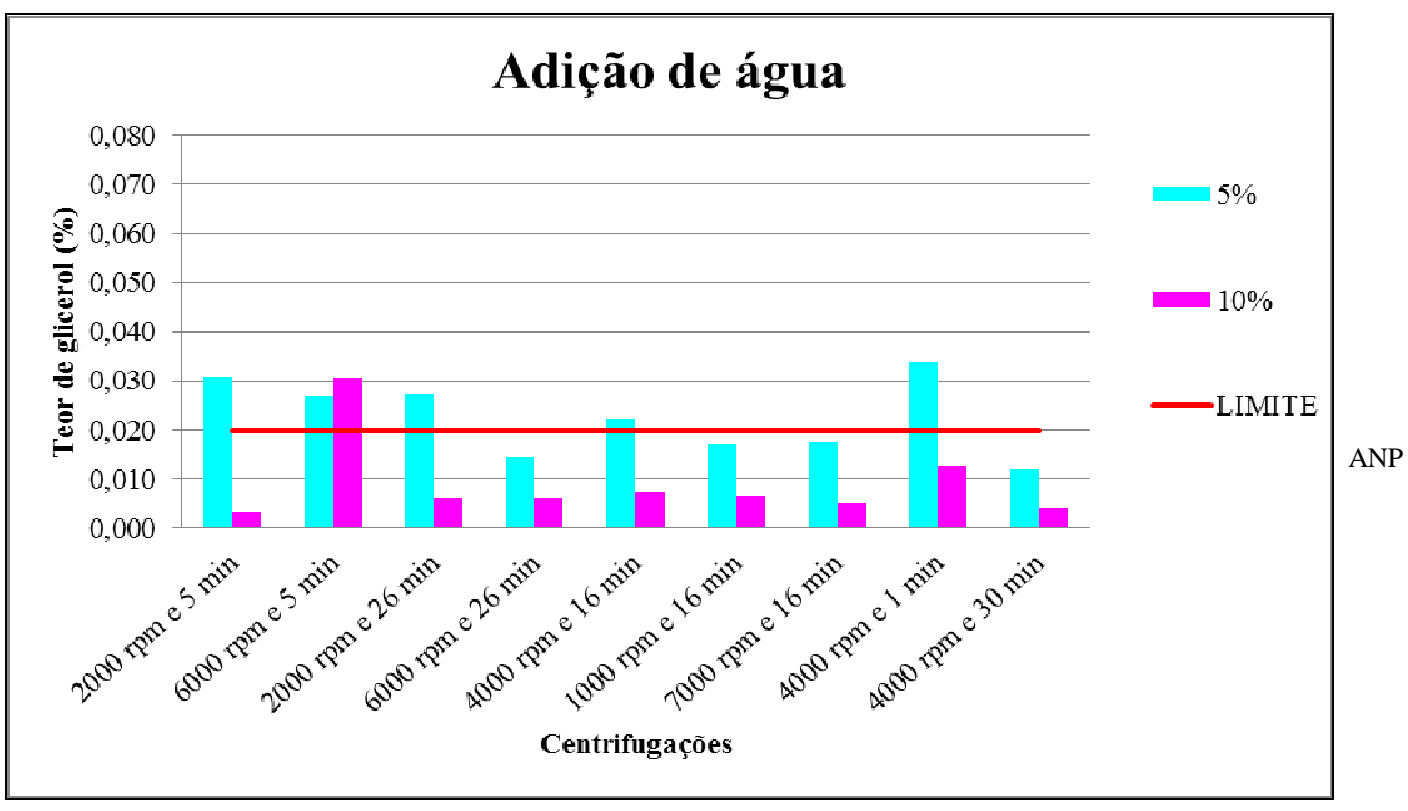

Figura 1 - Resultados da centrifugação do biodiesel com adição de água.

Na Figura 1, pode-se verificar que a adição de 5\% apresentou resultados do teor de glicerol dentro da especificação para as centrifugações com 6000 rpm por 26 minutos, 1000 rpm por 16 minutos, $7000 \mathrm{rpm}$ por 16 minutos e $4000 \mathrm{rpm}$ por 30 minutos.

$\mathrm{Na}$ adição de $10 \%$, pode-se verificar um melhor resultado para quase todas as centrifugações. Somente a centrifugação a $6000 \mathrm{rpm}$ por 5 minutos apresentou um teor de glicerol acima do permitido pela ANP. Um bom resultado é a centrifugação a $2000 \mathrm{rpm}$ por 5 minutos que se torna viável pela rotação e tempo baixos.

A Figura 2 apresenta a superfície de resposta para a adição de $10 \%$ de água ao biodiesel de canola. 


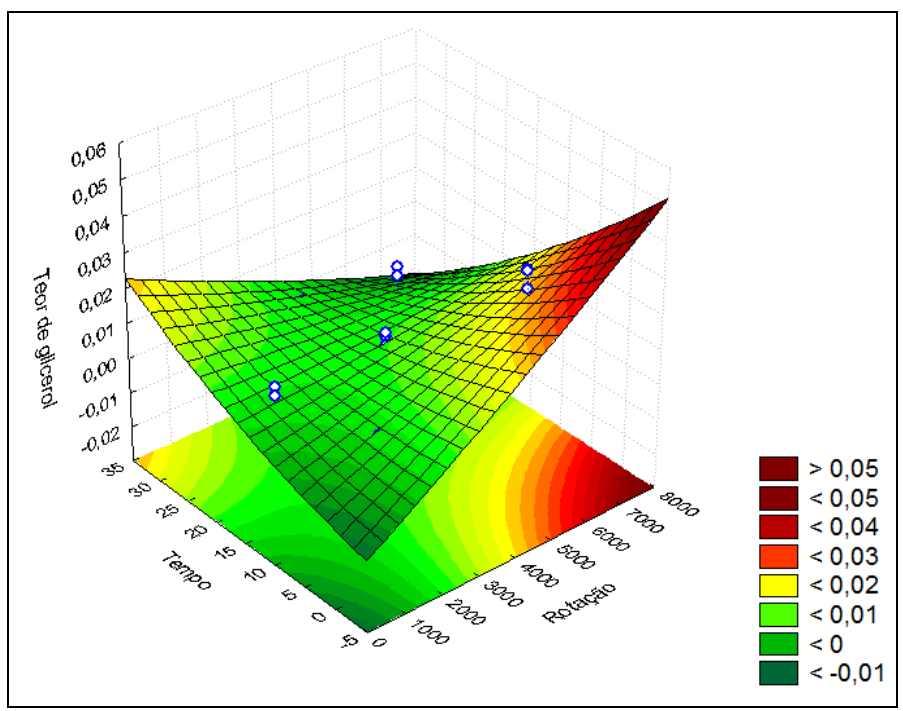

Figura 2 - Superfície de resposta com adição de $10 \%$ de água.

Na Figura 2, pode-se observar uma ampla utilização de rotação e tempo de centrifugação, sendo necessário evitar somente rotações altas com tempos muito baixos. Verifica-se que o tempo deve aumentar proporcionalmente com a rotação para se obter bons resultados.

A separação das fases biodiesel e glicerol ocorre em função da adição de água e proporciona a formação de uma fase dispersa aquosa, contendo glicerol, catalisador, sais e outras substâncias solúveis em água, distinta da fase rica em ésteres etílicos e óleo não reagido. Ou seja, a presença de água diminui a solubilidade dos ésteres no glicerol, proporcionando a coalescência do glicerol em gotículas maiores, e, assim, a sua decantação é mais rápida (Saleh et al., 2010).

Considerando o processo de produção e purificação do biodiesel, temos que, do ponto de vista econômico e ambiental, a proporção de 10\% de água, rotação de $2000 \mathrm{rpm}$ e tempo de 5 minutos são as melhores condições encontradas.

Percebe-se que, para concentrações baixas de água, são necessários tempos maiores de centrifugação. Assim sendo, é necessário realizar uma análise de custo a fim de verificar o que seria mais viável: o uso de uma concentração maior (10\%), com tempos e rotações menores (2000 rpm e 5 minutos) ou concentrações menores (5\%), com rotações e tempos maiores (6000 rpm e 26 minutos).

\section{Conclusões}


A centrifugação do biodiesel sem a pré-retirada do etanol, não promove a separação de fases, sendo necessário a adição de água para que a purificação por centrifugação ocorra de forma eficiente.

Nas condições em que os ensaios foram conduzidos, concluiu-se que, para a adição de 5\% de água ao biodiesel, a centrifugação a $1000 \mathrm{rpm}$ por 16 minutos mostrou-se muito eficaz para a purificação. Para a adição de $10 \%(\mathrm{~m} / \mathrm{m})$ de água ao biodiesel, a centrifugação com $2000 \mathrm{rpm}$ por 5 minutos também apresentou um bom resultado para o teor de glicerol, sendo viável por utilizar um tempo menor de centrifugação.

Percebe-se que, para baixas concentrações, são necessários tempos maiores de centrifugação. Assim sendo, é necessário realizar uma análise de custo a fim de verificar o que seria mais viável.

O processo de centrifugação para purificação de biodiesel em substituição ao processo convencional mostrou-se eficaz pela diminuição do tempo do processo, redução da quantidade de efluente gerado e economia de energia para a retirada do etanol e no aquecimento da água de lavagem.

\section{Agradecimentos}

Agradeço ao apoio da Coordenação de Aperfeiçoamento de Pessoal de Nível Superior CAPES - Brasil.

\section{Referências}

ANP, 2013. Agência Nacional do Petróleo, Gás Natural e Biocombustíveis. Relatório Mensal do Biodiesel. Disponível em: <http://www.anp.gov.br/?pg=58819\&m=\&t1=\&t2=\&t3 $=\& \mathrm{t} 4=\& a \mathrm{r}=\& \mathrm{ps}=\&$ cachebust=1325941677039>. Acesso em: 15 jul. 2014 .

DIB, F. H. Produção de biodiesel a partir de óleo residual reciclado e realização de testes comparativos com outros tipos de biodiesel e proporções de mistura em um moto-gerador. Dissertação (Mestrado em Engenharia Mecânica) - Universidade Estadual Paulista. Faculdade de Engenharia de Ilha Solteira, Ilha Solteira, São Paulo, 2010.

GOMES, M. C. S.; ARROYO, P. A.; PEREIRA, N. C. Influence of acidified water addition 
on the biodiesel and glycerol separation through membrane technology. Journal of Membrane Science. v. 431, p. 28 - 36, 2013.

PARENTE, E. J. S. Biodiesel: uma aventura tecnológica num país engraçado. Fortaleza: Unigráfica, 2003. 66p.

SALEH, J.; TREMBLAY, A.Y.; DUBÉ, M.A. Glycerol removal from biodiesel using membrane separation technology. Fuel, v. 89, p. 2260-2266, 2010.

STELUTI, A. J. C. Estudo do Processo de Separação das Fases Biodiesel-Glicerina por Centrifugação. Maringá: Universidade Estadual de Maringá, 2007. 50 p. Dissertação (Mestrado em Engenharia Química). 